\title{
Factors Influencing Nursing Students' Empowerment: A Literature Review
}

\author{
Tahany Fareed Al-Niarat, Fathieh Abumoghli \\ School of Nursing, University of Jordan, Amman, Jordan \\ Email: tahany-fareed@hotmail.com, fathieh@ju.edu.jo
}

How to cite this paper: Al-Niarat, T.F. and Abumoghli, F. (2019) Factors Influencing Nursing Students' Empowerment: A Literature Review. Open Journal of Nursing, 9, 1240-1251.

https://doi.org/10.4236/ojn.2019.912090

Received: November 8, 2019

Accepted: December 16, 2019

Published: December 19, 2019

Copyright $\odot 2019$ by author(s) and Scientific Research Publishing Inc. This work is licensed under the Creative Commons Attribution International License (CC BY 4.0).

http://creativecommons.org/licenses/by/4.0/

(c) (i) Open Access

\begin{abstract}
Aim: The purpose of this literature review is to locate the available literature that addresses the factors influencing the nursing students' empowerment. Background: Nursing students' empowerment is an essential element to enhance the learning process. Nursing students' learning experiences in the classroom and in the clinical placement play vital role in their empowerment. Data Source: A review of relevant literature using the following databases: CINAHL, ERIC \& EBSCO. Methods: A literature review of, peer-reviewed research, Master/PhD dissertations full text and published on the listed databases between (2003-2019) was done. Results: A final review of 16 studies was included, quantitative and qualitative studies that discussed the factors that may affect nursing students' empowerment were included in this review. Conclusion: Viewed articles revealed that nursing students' empowerment may be affected by many factors. According to previous literature and according to the authors' perspective, the retrieved articles categorized as followings: intrapersonal empowerment, learner orientation to learning, teaching-learning experiences, and the learning environment that influencing the learners' empowerment.
\end{abstract}

\section{Keywords}

Empowerment, Nursing Student, Learning, Clinical Placement

\section{Introduction}

Empowerment is a concept developed in the last five decades. Empowerment at the beginning was discussed as manager-employee relationships, and how the managers can create trustful relationships with their employees. Then, the concept of motivation came into an organizational context to enhance these relationships until it developed to empowerment [1]. Cangaro (1989) described 
empowerment as "the act of strengthening an individual's belief in his or her sense of effectiveness". According to Chandler [2] empowerment means "enable to act" and "enabling individuals to feel effective so they can successfully execute their jobs". Additionally, Kanter [3] proposed that the organizational conditions act positively on an individual's internal motivation and his/her intent to be empowered. The organizational conditions described by Kanter as the accessibility to resources, opportunity, information, and support. Without these conditions, the individual would not accomplish the desired organizational outcomes.

Empowerment is a combination of organizational empowerment and psychological empowerment. Psychological empowerment is intrapersonal, interactional, and behavioural [4]. Zimmerman \& Warschausky proposed that controlling and using the organizational resources effectively support and enhance the intrapersonal empowerment.

Spreitzer [5] expanded Kanter's categorized organizational empowerment into an intrapersonal empowerment conceptualization and operationalization. Intrapersonal empowerment is cognitive in nature. The components of intrapersonal empowerment are the confidence: the individuals perceive themselves confident of their skills and tasks they perform. The meaningfulness: the individuals' goals are matching the organizational goals, so they become aware of the importance and the meaning of their actions. The impact: the individuals' understand that they have an impact within their context [5]. In last decades nursing researchers paid attention to the concept of empowerment to enhance nursing outcomes, particularly in nursing education [6] [7] [8] [9].

\section{Review Purpose}

The purpose of this literature review is to illustrate the available literature that addresses the factors influencing the nursing students' empowerment in order to draw out conclusions and recommendations to facilitate students' empowerment.

\section{Materials and Methods}

\subsection{Search Strategy}

Searching strategies in this study were based on an electronic database, the $\mathrm{Cu}$ mulative Index to Nursing and Allied Health Literature (CINAHL), Educational Resources Information Centre (ERIC), EBSCO, Google scholar industries from (2003-2019). Keywords used in this study for searching were empowerment, nursing students, nursing educators, teaching style, learning outcomes, nursing learning, clinical learning, clinical placement, and factors. Boolean operators (AND, OR) have been applied separately and in combination with the key words to expand, combine, or exclude keywords in a search to narrow down the results.

\subsection{Inclusion Criteria}

This literature review paper included full text articles written in English, pub- 
lished between 2003-2019, and focused on nursing students.

\subsection{Search Outcomes}

The primary search at the database retrieved 645 articles. Then the duplicated and unrelated articles were removed. After screening by titles 17 articles were removed because they did not meet the inclusion criteria. Then articles were screened by abstract and the remained articles were $(n=205)$. Next, after full paper reviewing 75 studies remained. Final number of articles included in this review and met the inclusion criteria were 16 studies. The searching strategies are illustrated in (Figure 1).

\section{Results}

The retrieved literature related to the factors that may affect nursing students' empowerment were categorized under four sections. The first section defines and describes intrapersonal empowerment in the literature within the nursing education context. The second section describes and illustrates the related factors of learner orientation to learning. The third section defines and illustrates the related factors of teaching-learning experiences. The last section defines and describes the learning environment that influence the learners' empowerment. The retrieved studies are summarized in (Table 1).

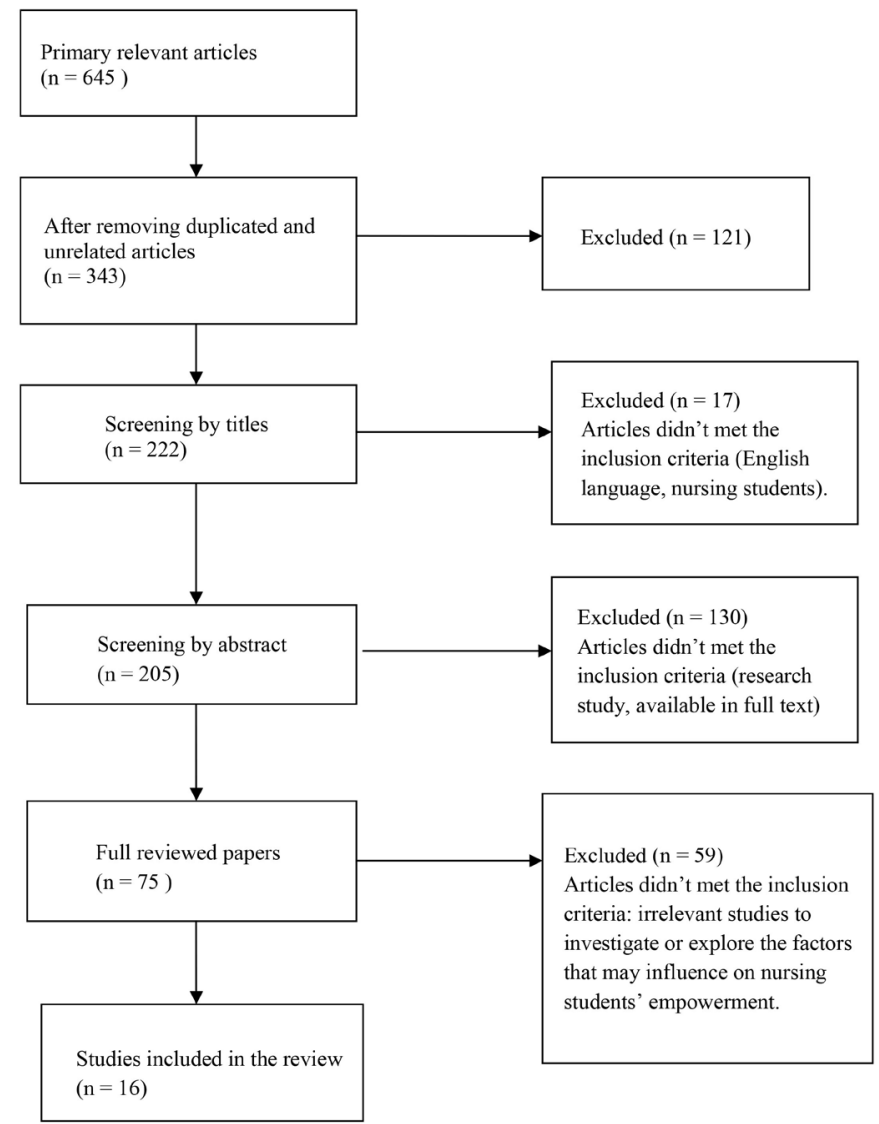

Figure 1. Searching strategy outcomes 
Table 1. Summary of the findings.

\begin{tabular}{|c|c|c|c|c|c|c|}
\hline Category & Authors/year & Aim & Sample & Study design & Main factors & Main results \\
\hline $\begin{array}{l}\text { Intrapersonal } \\
\text { empowerment }\end{array}$ & $\begin{array}{l}\text { Ahn \& Choi } \\
\text { (2015) }\end{array}$ & $\begin{array}{l}\text { To assess the factors affecting } \\
\text { the empowerment level of } \\
\text { undergraduate nursing } \\
\text { students in Korea during } \\
\text { clinical training }\end{array}$ & 307 & $\begin{array}{c}\text { A } \\
\text { cross-sectional } \\
\text { design. }\end{array}$ & $\begin{array}{l}\text { Learners' } \\
\text { characteristics. } \\
\text { Clinical } \\
\text { placement } \\
\text { characteristics. }\end{array}$ & $\begin{array}{l}\text { Nursing students' knowledge in decision making } \\
\text { in the clinical setting, students' self-esteem, being } \\
\text { valued as a learner, and clinical placement } \\
\text { influence the students' empowerment level }\end{array}$ \\
\hline & $\begin{array}{l}\text { Bradbury-Jones, } \\
\text { et al. (2010) }\end{array}$ & $\begin{array}{l}\text { To explore nursing students' } \\
\text { empowerment in clinical } \\
\text { practice }\end{array}$ & $\begin{array}{l}\text { Thirteen } \\
\text { first year } \\
\text { nursing } \\
\text { student till } \\
\text { third year. }\end{array}$ & $\begin{array}{l}\text { Qualitative } \\
\text { Longitudinal } \\
\text { design. }\end{array}$ & $\begin{array}{c}\text { Learners' } \\
\text { characteristics. }\end{array}$ & $\begin{array}{l}\text { The results showed that the internal level of } \\
\text { knowledge and confidence of the students are the } \\
\text { most common factors that may affect their } \\
\text { empowerment level }\end{array}$ \\
\hline & $\begin{array}{c}\text { Houser \& } \\
\text { Frymier (2009) }\end{array}$ & $\begin{array}{l}\text { To investigate the learner and } \\
\text { teacher characteristics in the } \\
\text { classroom that may affect the } \\
\text { learners' empowerment. }\end{array}$ & 297 & $\begin{array}{l}\text { Descriptive } \\
\text { design. }\end{array}$ & $\begin{array}{l}\text { Educators' } \\
\text { characteristics. } \\
\text { Learners' } \\
\text { characteristics. }\end{array}$ & $\begin{array}{l}\text { The teacher clarity and convenient } \\
\text { communication with student enhance the } \\
\text { sense of learner empowerment. } \\
\text { The student motivation to learn and his } \\
\text { individual characteristic as learning orientation } \\
\text { has a great influence on the sense of } \\
\text { empowerment. } \\
\text { Both the teacher characteristics and learner } \\
\text { characteristics are essential to increase the sense } \\
\text { of learner empowerment. }\end{array}$ \\
\hline & $\begin{array}{l}\text { Kirk, et al. } \\
\quad(2016)\end{array}$ & $\begin{array}{l}\text { To identify both intrapersonal } \\
\text { and environmental factors that } \\
\text { predict increased } \\
\text { empowerment and outcomes } \\
\text { associated with empowerment. }\end{array}$ & 381 & Survey & $\begin{array}{l}\text { Learners' } \\
\text { characteristics. } \\
\text { Clinical } \\
\text { placement } \\
\text { characteristics. }\end{array}$ & $\begin{array}{l}\text { The students' behavioural and academic } \\
\text { characteristics indicate that students who } \\
\text { reported a high level of intrapersonal } \\
\text { empowerment are less likely to be engaged in } \\
\text { trouble, less likely to skip class, more likely to } \\
\text { participate in activities extracurricular, and get } \\
\text { higher grades. }\end{array}$ \\
\hline $\begin{array}{l}\text { Learner } \\
\text { orientation to } \\
\text { learning }\end{array}$ & $\begin{array}{l}\text { Khater, } \\
\text { Akhu-Zaheya, } \\
\text { \& Shaban } \\
\text { (2014) }\end{array}$ & $\begin{array}{l}\text { Assess the stress types, } \\
\text { sources, and coping strategies }\end{array}$ & 597 & $\begin{array}{l}\text { A descriptive, } \\
\text { cross-sectional, } \\
\text { comparison } \\
\text { design. }\end{array}$ & $\begin{array}{l}\text { Learners' } \\
\text { attitudes toward } \\
\text { learning. }\end{array}$ & $\begin{array}{l}\text { The most common source of stress is the } \\
\text { assignment prior to the clinical training. Stress } \\
\text { was found to be less in senior nursing students in } \\
\text { comparison with junior students. Students } \\
\text { reported that the stress level decreased with their } \\
\text { academic progression, and how they become } \\
\text { more confident of their knowledge and skills. }\end{array}$ \\
\hline \multirow{3}{*}{$\begin{array}{l}\text { Learning- } \\
\text { teaching } \\
\text { experiences }\end{array}$} & $\begin{array}{l}\text { Papp, } \\
\text { Markkanen, \& } \\
\text { von Bonsdorff } \\
\quad(2003)\end{array}$ & $\begin{array}{l}\text { To describe the clinical } \\
\text { environment in relation to } \\
\text { clinical learning experiences } \\
\text { in Taiwan }\end{array}$ & 16 & $\begin{array}{l}\text { Qualitative } \\
\text { design } \\
\text { (unstructured } \\
\text { interview) }\end{array}$ & $\begin{array}{l}\text { Learners' } \\
\text { perception of the } \\
\text { teaching. } \\
\text { Learners' } \\
\text { attitudes toward } \\
\text { learning. }\end{array}$ & $\begin{array}{l}\text { Students stated that the feeling of appreciation } \\
\text { encourages them to show positive attitudes } \\
\text { toward learning. } \\
\text { Self-directed students, who are aware of their } \\
\text { limitations and potential had a sense of } \\
\text { responsibility toward learning }\end{array}$ \\
\hline & $\begin{array}{l}\text { Al-Hussami, } \\
\text { et al. (2011) }\end{array}$ & $\begin{array}{l}\text { To assess the nursing students' } \\
\text { relationship with their faculty }\end{array}$ & 275 & $\begin{array}{l}\text { A cross-section } \\
\text { design. }\end{array}$ & $\begin{array}{c}\text { Educators' } \\
\text { characteristics. }\end{array}$ & $\begin{array}{l}\text { The results of this study highlighted the role of } \\
\text { the teacher beyond presentation a class. Teachers } \\
\text { should open an interactive and collaborative } \\
\text { channels with students to improve the desired } \\
\text { learning outcomes. }\end{array}$ \\
\hline & Cakir (2015) & $\begin{array}{l}\text { To assess the teacher's } \\
\text { attitudes in the classroom }\end{array}$ & 322 & $\begin{array}{l}\text { A cross-section } \\
\text { design. }\end{array}$ & $\begin{array}{c}\text { Educators' } \\
\text { characteristics. }\end{array}$ & $\begin{array}{l}\text { The authoritarian attitudes of the teacher are to } \\
\text { control and nurturance in the classroom. } \\
\text { When teacher uses an authoritarian attitude by } \\
\text { controlling the classroom and in nurturance } \\
\text { context; they feel empowered and thus enhance } \\
\text { their learning process. }\end{array}$ \\
\hline
\end{tabular}




\section{Continued}

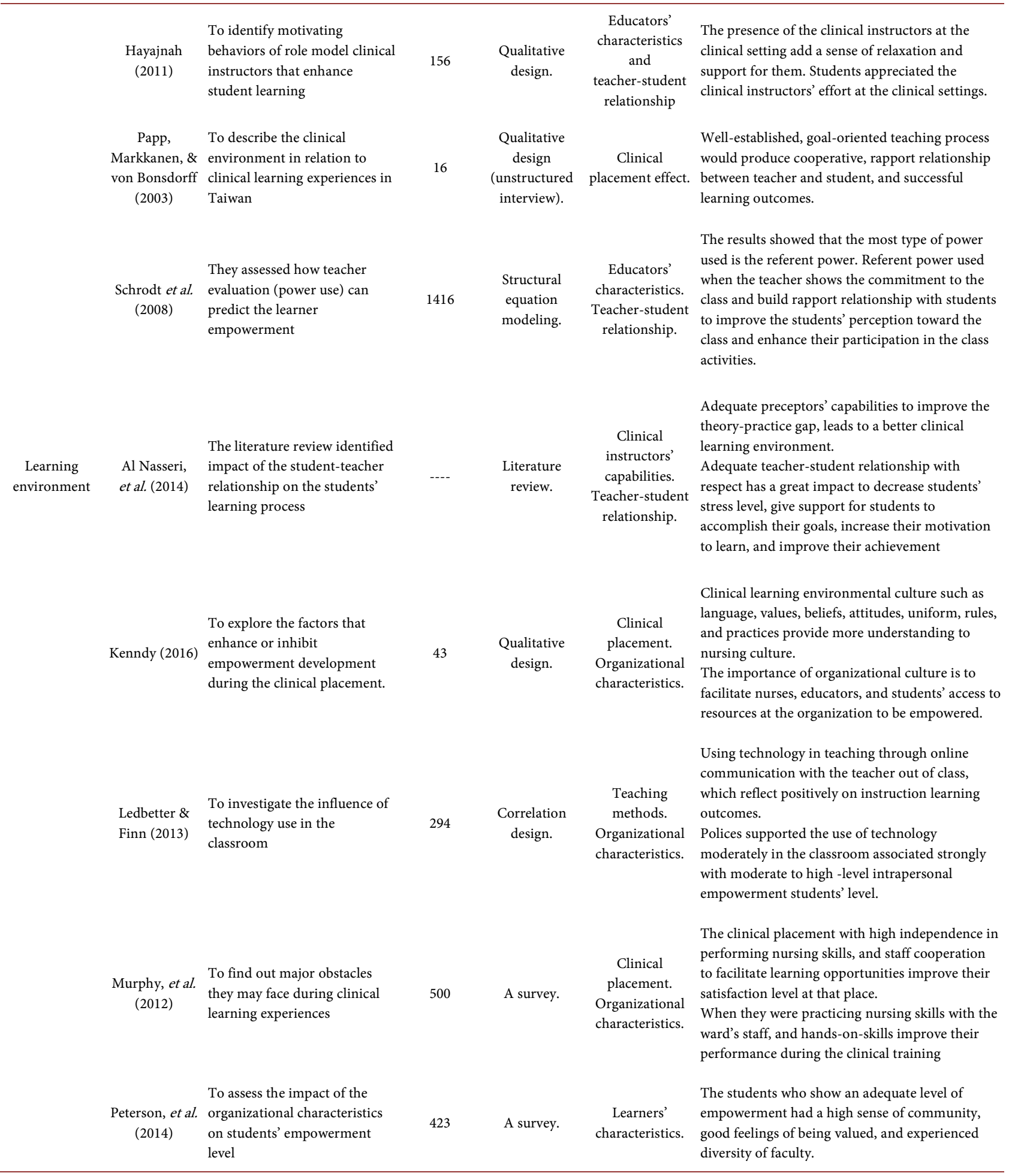

\subsection{Intrapersonal Empowerment}

A qualitative longitudinal study explored nursing students' empowerment in clinical practice, the study had started at first level to third level [9]. BradburyJones, et al. (2010) formed the Empowerment of Nursing Student in Clinical 
Practice: Spheres of Influence. This framework diagrams the factors, internal and external, that influence students' empowerment. It clarifies that the internal level of knowledge and confidence of the students are the most common factors that may affect their empowerment level. The external factors are numerous: 1) being valued as a learner, person, and team member makes them more empowered and makes their clinical learning experience more interesting. It considers that the instructor's role is to encourage students' participation which could foster their empowerment sensation. 2) The mentors and placement for students, the duration and frequency of placement influence the sense of students' empowerment. Students emphasized that frequent changes of clinical placement are problematic for them. 3) Cultural and structural/organizational influences, to what degree this placement is organized, have a positive impact on students' sense of empowerment. 4) Social and political factors, nursing policies within the nursing community, facilitate nursing students' sense of empowerment.

Based their study on the findings of this study, Ahn \& Choi [10] assessed the factors affecting the empowerment level of undergraduate nursing students in Korea during their clinical training. They reported that the nursing students had high empowerment level. The results revealed that the 307 nursing students' knowledge in decision making in the clinical setting, students' self-esteem, being valued as a learner, and clinical placement influence the students' empowerment level. They highlighted some factors that strongly influence learner empowerment, and enhance their learning experience, therefore improve the learning outcomes positively.

Furthermore, Kirk, et al. (2016) [11] assessed the381 students from five urban high schools in United States. They assessed the classroom factors (teacher-student relationship, and sense of community), and the individual characteristics (school attendance, school behaviour, participation in extracurricular activities, self-reported grades, and expectation for future academic attainment). The classroom factors strongly predicted the students' intrapersonal empowerment. Teacher-student relationship was manifested as the teacher use of power, teacher use of referent power and the student sense of community. Teachers' use of coercive power was associated with lower intrapersonal empowerment level of students. Moreover, the students' behavioural and academic characteristics indicated that students who reported a high level of intrapersonal empowerment were less likely to be engaged in trouble, less likely to skip classes, more likely to participate in extracurricular activities, and get higher grades.

Another Chinese study investigated the 300 senior nursing student' level of empowerment and its relation with clinical competencies [7]. The students reported a moderate level of empowerment in clinical learning. Moreover, the students showed a strong correlation between the empowerment level and clinical competencies level. This indicates the essence of intrapersonal empowerment of nursing students to perform their nursing skills in a competent and safe manner, which ensures high quality of patient's care. 
Houser \& Frymier [12] investigated the learner and teacher characteristics in the classroom that may affect the learner empowerment. Two hundred ninetyseven senior students at South western University completed the questionnaires. The results indicated that the teacher clarity and convenient communication with students enhance the sense of learner empowerment. Similarly, student motivation to learn and his/her individual characteristic and learning orientation has a great influence on the sense of empowerment. This study predicted that both the teacher characteristics and learner characteristics are essential to increase the sense of learner empowerment.

\subsection{Learner Orientation to Learning}

Personal characteristics during learning affect the learning process. Stress raised out by learning requirements is one of the factors that may alter students' clinical learning process [13]. It affects students' ability in problem-solving, decision making, and affect their self-esteem level. Chernomas Wanda \& Shapiro [14] emphasized the importance of clinical placement, instructor's role, and assignment preparation on fourth-year nursing students stress level and their expectations from the clinical experiences.

A Jordanian study assessed the stress sources in the clinical environment among nursing students [15]. It assessed the stress types and sources, and coping strategies of 597 nursing students from two public universities in Jordan. The most common source of stress was the assignment prior to the clinical training. Stress was found to be less among senior nursing students in comparison with junior students. Adult Health Nursing course I (second year) was associated with a higher level of students' stress in comparison with the Advance Nursing Training course (fourth year). Students reported that the most common coping strategies used to overcome these stressors were: problem-solving, keeping optimistic, and transference. Students reported that the stress level decreased with their academic progression as they become more confident of their knowledge and skills. This study showed that, with experience the students feel independent in the clinical environment and their capabilities to cope with stressors is enhanced and their learning outcomes are improved.

Unstructured interviews of 16 nursing students to describe the clinical environment in relation to clinical learning experiences were conducted in Taiwan. The students reported that they were appreciated by their teachers as learners. They stated that the feeling of appreciation encourages them to show positive attitudes toward learning [16]. Also, self-directed students, who are aware of their limitations and potential had a sense of responsibility toward learning. This study emphasized students' role and their ability in improving their learning outcomes [16].

\subsection{Learning-Teaching Experiences}

The terms "clinical instructors" and "clinical preceptors" which were used in nursing research interchangeably, referred to the nurse educator who teaches in 
the clinical area. A nurse educator is one who teaches both theory and the practice [17]. The teacher plays a strong role in learning-teaching experiences, thus teachers' attitudes toward students in the classroom or in the clinical area and their attitudes in the teaching process, have a great impact on students' learning outcomes. Students-faculty members relationship was assessed in Jordan, at a public university as perceived by the students [18]. The students reported positive learning outcomes (better academic grades) when they interact more with their teachers after the classroom to discuss courses and to discuss further issues. The results of this study highlighted the role of the teacher beyond class presentation. The study concluded that teachers should open an interactive and collaborative channels with students to improve the desired learning outcomes.

Furthermore, support from the teacher in the classroom and clinical environment makes learning a desirable experience [16]. Well-established, goaloriented teaching process would produce cooperative, rapport relationship between teacher and student, and successful learning outcomes [16].

The teacher-student relationship is of considerable value to enhance learner empowerment [19]. The empowered students are more likely to recognize the meaningfulness of the course, feel more sense of self-efficacy and competence to complete the tasks, and ability to identify the impact of the course. Schrodt, P., et al. [19] assessed how teachers' evaluation (power use) can predict the learners' empowerment. The results showed that the most type of power use within the five types of power that predict the learner empowerment is the referent power. Referent power is reflected when the teacher shows the commitment to the class and builds rapport relationship with students to improve their perception of the class and enhance their participation in the class activities.

On the other hand, the teacher authoritarian attitudes in the classroom were assessed by university students [6]. The authoritarian attitudes of the teacher are to control and nurture students in the classroom. The students reported that when they perceived that the teacher uses an authoritarian attitude by controlling the classroom in a nurturing context, they felt empowered and this enhanced their learning.

Jordanian nursing students perception of their clinical instructor's role at clinical setting were described by Hayajneh [20]. The students reported that particular clinical instructors' characteristics were perceived as motivating for them at clinical setting to learn. Also, they reported that the presence of the clinical instructors at the clinical setting adds a sense of relaxation and support for them. Students appreciated the clinical instructors' effort at the clinical settings; they described how clinical instructors act in a unique way with them. All these behaviors affect the clinical learning experience positively, and the students achieved their desired learning objectives.

\subsection{Learning Environment}

The learning environment for nursing students is a combination of clinical learning and classroom learning.The clinical learning environment (CLE) is the 
interactive network of forces within the clinical setting that influence the students' clinical learning outcomes [21]. The classroom learning is more structured than the clinical learning [22]. Identification of the factors that influence the clinical learning environment help to implement strategies to enhance desirable learner outcomes. Few but not limited studies focus on the impact of a learning environment, assessing new learning methods, and assessing the learning culture to enhance learning motivation [17] [23] [24] [25].

The literature reviewed the impact of the student-teacher relationship on the students' learning process [17]. The reviewed studies indicated that preceptor's capabilities improve the theory-practice gap, which leads to a better clinical learning environment. Also, adequate and respectful teacher-student relationship has a great impact to decrease students' stress level, give support for students to accomplish their goals, increase their motivation to learn, and improve their achievement. Thus, it would affect positively the students' learning outcomes.

Technology posses students to enhance the learning process, teachers strive to administer new innovation into teaching instructions to improve the learning instructions' outcomes. Ledbetter \& Finn [26] investigated the influence of technology use in the classroom at South north University students and its effect on the students' intrapersonal empowerment level. The study used technology in teaching through online communication with the teacher out of class, which reflected positively on learning outcomes. The results revealed that policies that encourage the use of technology moderately in the classroom lead to strongly with moderate to high -level intrapersonal empowerment students' level.

Students would feel empowered when they reached to their expectations, they describe themselves as meaningful in the class, competent at class activities, and their activities have an impact in the class. They could feel the sense of empowerment. The important issue is how the teacher encourages students to reach a sense of empowerment. The teacher should be creative and improve the learning environment to enhance the students' intrapersonal empowerment level [26].

A study was conducted on undergraduate students and directed to find out major obstacles they may face during clinical learning experiences [23]. Five hundred, third-year undergraduate nursing student at Wales/United Kingdom were asked to assess three different clinical placement during that year. Students reported that the clinical placement with high independence in performing nursing skills, and staff cooperation to facilitate learning opportunities improve their satisfaction level at that place. They reported that they were practicing nursing skills with the ward's staff, and hands-on-skills improved their performance during the clinical training [23].

Organizations such as schools, strive to cultivate their resources and capabilities to be described as an empowered organization. The empowered organization's characteristics are described to facilitate the access to information and diversity of faculty [24]. Peterson, Farmer, and Zippay assessed the impact of organizational characteristics on students' empowerment level. The results re- 
flected that the students who show an adequate level of empowerment had a high sense of community, good feelings of being valued, and experienced diversity of faculty. In this study, the sense of community is the result of students' access to information, had the opportunity to participate in extracurricular activities, and practice decision-making skills in some teaching issues.

The power in the clinical environment is the effective use of resources to get a sense of empowerment. The ward/unit culture contributes to nursing students' experience in clinical placement. Clinical learning environmental culture such as language, values, beliefs, attitudes, uniform, rules, and practices provide more understanding to nursing culture. The importance of organizational culture is to facilitate nurses, educators, and students' access to resources at the organization to be empowerment. This condition is associated positively with nursing students' outcomes (managerial support, good student and healthcare providers relationship, higher patient care quality, and higher students' satisfaction level [25]. Clinical training plays an important role to facilitate the implementation of the desired learning objectives. The environment, instructors, and staff work collaboratively to facilitate learning opportunities to develop their knowledge, skills, and clinical teaching [27].

\section{Conclusions and Recommendation}

The reviewed literature illustrated the comprehensive definition of empowerment within the nursing students' context. The reviewed articles showed the importance of empowerment as personal characteristic, and the personal factors that may affect it. And that, the empowerment is affected by the organizational structure and culture. The reviewed articles supported that the helpful and supportive learning environment is an empowering environment in addition to intimate teacher-learner relationship. It also clarifies the major factors that may influence nursing students' empowerment level. Additionally, it clarifies how these factors may influence on nursing students' learning process and desired learning outcomes.

The reviewed articles showed the essence of nursing educators' capabilities to empower students through building rapport relationship, supporting them, and facilitating learning opportunities.

The classroom learning and clinical learning are essentially simultaneously; as known, the nursing student spends the majority of their learning experience in the clinical environment.

The learning placement plays strong role to create learning chances for nursing students. The clinical instructors, administrators, and decision makers in the teaching hospitals should facilitate adequate clinical placement for nursing students to achieve their goals and objectives of required curriculum. Thus it will have positive impact on their comprehensive clinical skills, decision-making, self-esteem, problem-solving skills, and on patients' care. In addition, the ward staff and other healthcare providers should provide support and the available learning opportunities for nursing students during their clinical learning. 


\section{Conflicts of Interest}

The authors declare no conflicts of interest regarding the publication of this paper.

\section{References}

[1] Conger, J.A. (1989) Leadership: The Art of Empowering Others. Academy of Management Perspectives, 3, 17-24. https://doi.org/10.5465/ame.1989.4277145

[2] Chandler, G.E. (1992) The Source and Process of Empowerment. Nursing Administration Quarterly, 16, 65-71. https://doi.org/10.1097/00006216-199201630-00011

[3] Kanter, R. (1993) Men and Women of the Corporation. 2nd Edition, Basic Book, New York.

[4] Zimmerman, M.A. and Warschausky, S. (1998) Empowerment Theory for Rehabilitation Research: Conceptual and Methodological Issues. Rehabilitation Psychology, 43, 3. https://doi.org/10.1037//0090-5550.43.1.3

[5] Spreitzer, G.M. (1995) An Empirical Test of a Comprehensive Model of Intrapersonal Empowerment in the Workplace. American Journal of Community Psychology, 23, 601-629. https://doi.org/10.1007/BF02506984

[6] Cakır, S.G. (2015) Authoritative Approach and Student Empowerment among University Students. Procedia-Social and Behavioral Sciences, 186, 151-154. https://doi.org/10.1016/j.sbspro.2015.04.078

[7] Liao, R.-X. and Liu, Y.-H. (2016) The Impact of Structural Empowerment and Psychological Capital on Competence among Chinese Baccalaureate Nursing Students: A Questionnaire Survey. Nurse Education Today, 36, 31-36. https://doi.org/10.1016/j.nedt.2015.07.003

[8] Bradbury-Jones, C., Sambrook, S. and Irvine, F. (2011) Empowerment and Being Valued: A Phenomenological Study of Nursing Students' Experiences of Clinical Practice. Nurse Education Today, 31, 368-372. https://doi.org/10.1016/j.nedt.2010.07.008

[9] Bradbury-Jones, C., Irvine, F. and Sambrook, S. (2010) Empowerment of Nursing Students in Clinical Practice: Spheres of Influence. Journal of Advanced Nursing, 66, 2061-2070. https://doi.org/10.1111/j.1365-2648.2010.05351.x

[10] Ahn, Y.-H. and Choi, J. (2015) Factors Affecting Korean Nursing Student Empowerment in Clinical Practice. Nurse Education Today, 35, 1301-1306. https://doi.org/10.1016/j.nedt.2015.08.007

[11] Kirk, C.M., Lewis, R.K., Brown, K., Karibo, B. and Park, E. (2016) The Power of Student Empowerment: Measuring Classroom Predictors and Individual Indicators. The Journal of Educational Research, 109, 589-595. https://doi.org/10.1080/00220671.2014.1002880

[12] Houser, M. and Frymier, A. (2009) The Role of Student Characteristics and Teacher Behaviors in Students' Learner Empowerment. Communication Education, 58, 35-53. https://doi.org/10.1080/03634520802237383

[13] Chen, Y.-W. and Hung, C.-H. (2014) Predictors of Taiwanese Baccalaureate Nursing Students' Physio-Psycho-Social Responses during Clinical Practicum. Nurse Education Today, 34, 73-77. https://doi.org/10.1016/j.nedt.2013.02.021

[14] Chernomas Wanda, M. and Shapiro, C. (2013) Stress, Depression, and Anxiety among Undergraduate Nursing Students. International Journal of Nursing Education Scholarship, 10, 255. https://doi.org/10.1515/ijnes-2012-0032 
[15] Khater, W., Akhu-Zaheya, L. and Shaban, I. (2014) Sources of Stress and Coping Behaviours in Clinical Practice among Baccalaureate Nursing Students. International Journal of Humanities and Social Science, 4, 194-202.

[16] Papp, I., Markkanen, M. and von Bonsdorff, M. (2003) Clinical Environment as a Learning Environment: Student Nurses' Perceptions Concerning Clinical Learning Experiences. Nurse Education Today, 23, 262-268. https://doi.org/10.1016/S0260-6917(02)00185-5

[17] Al Nasseri, Y.S., Renganathan, L., Al Balushi, A. and Al Nasseri, F. (2014) Impact of Students-Teacher Relationship on Student's Learning: A Review of Literature. International Journal of Nursing Education, 6, 167. https://doi.org/10.5958/j.0974-9357.6.1.034

[18] Al-Hussami, M., Saleha, M.Y.N., Hayajneh, F., Abdalkader, R.H. and Mahadeen, A.I. (2011) The Effects of Undergraduate Nursing Student-Faculty Interaction Outside the Classroom on College Grade Point Average. Nurse Education in Practice, 11, 320-326. https://doi.org/10.1016/j.nepr.2011.02.004

[19] Schrodt, P., et al. (2008) Learner Empowerment and Teacher Evaluations as Functions of Teacher Power Use in the College Classroom. Communication Education, 57, 180-200. https://doi.org/10.1080/03634520701840303

[20] Hayajneh, F. (2011) Role Model Clinical Instructor as Perceived by Jordanian Nursing Students. Journal of Research in Nursing, 16, 23-32. https://doi.org/10.1177/1744987110364326

[21] Dunn, S.V. and Burnett, P. (1995) The Development of a Clinical Learning Environment Scale. Journal of Advanced Nursing, 22, 1166-1173. https://doi.org/10.1111/j.1365-2648.1995.tb03119.x

[22] Masilaca, O., Kumar, A. and Balekiwai, S. (2018) Clinical Learning Environment and Clinical Learning Outcomes as Perceived by Final Year Baccalaureate Nursing Students in Fiji National University, the Republic of Fiji. Journal of Nursing and Health Sciences, 4, 23-31.

[23] Murphy, F., Rosser, M., Bevan, R., Warner, G. and Jordan, S. (2012) Nursing Students' Experiences and Preferences Regarding Hospital and Community Placements. Nurse Education in Practice, 12, 170-175.

https://doi.org/10.1016/j.nepr.2011.12.007

[24] Peterson, N.A., Farmer, A.Y. and Zippay, A. (2014) The Implicit Curriculum in an Urban University Setting: Pathways to Students' Empowerment. Journal of Social Work Education, 50, 630-647. https://doi.org/10.1080/10437797.2014.947163

[25] Kennedy, S. (2016) An Exploration of Empowerment amongst Final-Year Undergraduate Nursing Students While on Clinical Placement in Ireland Using Social Domain Theory. University of Salford, Manchester.

[26] Ledbetter, A.M. and Finn, A.N. (2013) Teacher Technology Policies and Online Communication Apprehension as Predictors of Learner Empowerment. Communication Education, 62, 301-317. https://doi.org/10.1080/03634523.2013.794386

[27] Nabolsi, M., Zumot, A., Wardam, L. and Abu-Moghli, F.A. (2012) The Experience of Jordanian Nursing Students in Their Clinical Practice. Procedia-Social and Behavioral Sciences, 46, 5849-5857. https://doi.org/10.1016/j.sbspro.2012.06.527 